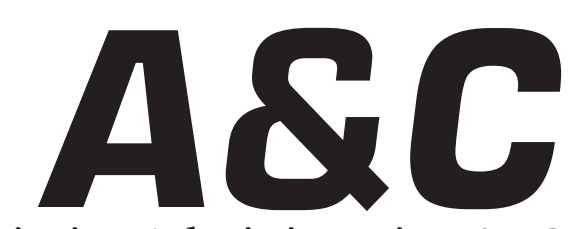

Revista de Direito Administrativo \& Constitucional

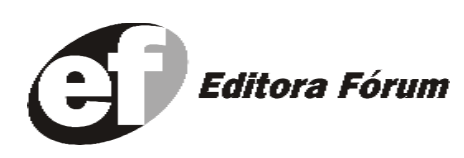

A\&C R. de Dir. Administrativo e Constitucional, Belo Horizonte, ano 4, n.16, p. 1-255, abr.jun. 2004 


\section{A\&C REVISTA DE DIREITO ADMINISTRATIVO E CONSTITUCIONAL}

\section{IPDA}

Instituto Paranaense

de Direito Administrativo

Direção Geral

Romeu Felipe Bacellar Filho

Direção Editorial

Paulo Roberto Ferreira Motta

Direção Executiva

Emerson Gabardo

Conselho de Redação

Edgar Chiuratto Guimarães

Adriana da Costa Ricardo Schier

Célio Heitor Guimarães

Conselho Editorial

\section{Adilson Abreu Dallari Lúcia Valle Figueiredo}

Alice Gonzáles Borges Manoel de Oliveira Franco Sobrinho

Carlos Ari Sundfeld (in memoriam)

Carlos Ayres Britto Marçal Justen Filho

Carlos Delpiazzo Marcelo Figueiredo

Cármen Lúcia Antunes Rocha Márcio Cammarosano

Celso Antônio Bandeira de Mello Maria Cristina Cesar de Oliveira

Clèmerson Merlin Clève Nelson Figueiredo

Clóvis Beznos Odilon Borges Junior

Enrique Silva Cimma Pascual Caiella

Eros Roberto Grau Paulo Eduardo Garrido Modesto

Fabrício Motta Paulo Henrique Blasi

Guilhermo Andrés Muñoz Paulo Neves de Carvalho

Jorge Luís Salomoni Paulo Ricardo Schier

José Carlos Abraão Pedro Paulo de Almeida Dutra

José Eduardo Martins Cardoso Regina Maria Macedo Nery Ferrari

José Luís Said Rogério Gesta Leal

José Mario Serrate Paz Rolando Pantoja Bauzá

Juan Pablo Cajarville Peruffo Sérgio Ferraz

Juarez Freitas Valmir Pontes Filho

Julio Rodolfo Comadira Yara Stropa

Luís Enrique Chase Plate Weida Zancaner

Os conceitos emitidos em trabalhos assinados são de responsabilidade de seus autores, que gozam de inteira liberdade de opinião. e-mail para remessa de artigos, pareceres e contribuições: e.gab.@uol.com.br

ou conselho@editoraforum.com.br Endereço para envio de contribuições: Editora Fórum

Revista A\&C, Av. Afonso Pena, 2770, 15\%16ª andar, Funcionários, CEP 30130-007 - Belo Horizonte - MG

A\&C Revista de Direito Administrativo e Constitucional. Ano 3, n. 11, jan./mar. 2003. Belo Horizonte: Fórum, 2003.

Trimestral

ano 1, n.1, 1999 até ano 2, n.10, 2002 publicada pela Editora Juruá em Curitiba

ISSN: $1516-3210$

1. Direito Administrativo. 2. Direito Constitucional. I. Fórum.

CDD: 342 CDU: 33.342
Editor responsável: Luis Cláudio Rodrigues Ferreira Projeto gráfico: Luis Alberto Pimenta

Diagramação: Anderson Pimenta

Revisora: Olga M. A. Sousa

Pesquisa jurídica: Fátima Ribeiro - OAB/MG 74868 Bibliotecária: Nilcéia Lage de Medeiros -

CRB 1545/MG - 6 a região

(C) Editora Fórum Ltda 2004.

Proibida a reprodução total ou parcial desta obra, por qualquer meio eletrônico, inclusive por processos xerográficos, sem autorização expressa do editor.

Distribuída em todo o território nacional

Assinaturas e comercialização:

Editora Fórum, Av. Afonso Pena, 2770, 15-16 andar, Funcionários, CEP 30130-007 - Belo Horizonte - MG Tel.: (31) 2121-4900 - 0800 704-3737

e-mail: editoraforum@editoraforum.com.br site: www.editoraforum.com.br 


\title{
Rodovias Federais: Delegação a Estados, Concessão e Encampação
}

\author{
Carlos Ari Sundfeld \\ Jacintho Arruda Câmara \\ Professores da Faculdade de Direito da PUC/SP e Coordenadores da Especialização em Direito \\ Administrativo na Escola de Direito da FGV-SP
}

\section{Introdução}

A Lei Federal n ${ }^{\circ}$ 9.277, de 10 de maio de 1996, autorizou a União a delegar aos Municípios, aos Estados da Federação e ao Distrito Federal a administração e exploração de suas rodovias, o que o ente delegado pode fazer tanto diretamente como por meio de concessão a empresas privadas. A originalidade da situação - a exploração de um bem federal ser concedida a particulares não por seu titular, mas pelo Estado - suscita curiosidade quanto ao papel que ficou reservado à União. Será que ela tem poderes e responsabilidades incidentes na relação jurídica instituída pela concessão?

Para debater a questão, parece interessante focar a vista no problema, sempre delicado, da extinção do contrato, muito especialmente naquela operada por razões de interesse público: a encampação. Há participação da União em eventual procedimento de encampação? $\mathrm{O}$ ato acarreta para ela alguma responsabilidade financeira? ${ }^{1}$

Muito embora o contrato de concessão seja celebrado pelo Estado, é inegável a existência de interesse e de repercussões jurídicas que afetem a União. Isto se deve, basicamente, ao fato de tal contrato envolver bem integrante de seu patrimônio (as rodovias federais). Mas o que nos cabe é identificar quais as conseqüências jurídicas mais significativas que a encampação desses contratos poderia trazer em relação à União. Em primeiro lugar analisaremos a necessidade de legislação federal específica para que seja realizada a encampação; depois, faremos a abordagem dos reflexos patrimoniais que podem recair sobre a União.

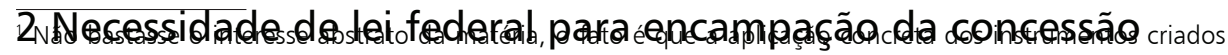
pela lei vem recentemente gerando grande preocupação e polêmica exatamente no tocante à encampação. Um caso tem mobilizado atenções: o do Estado do Paraná. Por meio de convênio firmado entre as respectivas entidades da Federação, a administração de certas rodovias passou da União ao Estado. Como administrador das rodovias, este outorgou concessão desses bens a empresas particulares. Porém, editou posteriormente uma série de leis que autorizaram a encampação das rodovias dadas em concessão (Leis Estaduais de n.os 14.061, 14.062, 14.063, 14.064 e 14.066, publicadas em 7 de julho de 2003). Aí iniciou-se o debate em torno do poder de intervenção que a União Federal teria no caso e de sua responsabilidade.
} 


\subsection{Necessidade de lei}

Como se sabe, a concessão representa um instrumento jurídico por meio do qual a oferta de bens ou serviços públicos é delegada a particulares. Ao transferir o ônus pela criação ou manutenção das utilidades oferecidas à população, a concessão também outorga ao concessionário direitos relacionados à exploração econômica do bem ou serviço delegado. Ou seja, em troca dos investimentos, o Poder Público oferece, basicamente, a exploração econômica da função delegada por um determinado período de tempo.

É fundamental a existência de garantias relacionadas à manutenção do direito de exploração do bem ou serviço pelo prazo estipulado para que se torne viável economicamente a delegação de tais atribuições públicas a particulares. Sem respaldo jurídico que lhe assegure o retorno do investimento, por óbvio, não haveria interesse da iniciativa privada em assumir os custos da criação ou manutenção de infra-estrutura pública.

Tendo em vista a importante circunstância acima descrita, a legislação geral sobre concessões disciplinou o instituto da encampação. A encampação é a forma de extinção do contrato de concessão que se dá por razões de interesse público. Nesta via, a extinção do contrato não deriva de culpa do concessionário ou de qualquer outra razão que implique descumprimento de obrigações legais ou contratuais por quaisquer das partesenvolvidas. O motivo da extinção é a conformação de um novo interesse público, que aponta no sentido da retomada da execução direta do serviço ou administração da obra pelo próprio Poder Concedente.

A encampação, portanto, confere a uma das partes (o Poder Concedente) a possibilidade de ruptura unilateral do contrato. Para que tal mecanismo não representasse um fator de extrema insegurança, que inviabilizasse a realização de investimentos privados, foram conferidas garantias especiais ao contratado (concessionário). Parte delas envolve aspectos econômicos do contrato, tal como a necessidade de indenização prévia, assegurada pela lei (tema a ser tratado especificamente no tópico seguinte). A outra grande garantia envolve diretamente o tema a ser abordado neste item: a necessidade de prévia e específica autorização legislativa.

Além de mecanismos econômicos de compensação pela ruptura do contrato, a legislação geral de concessões (Lei no 8.987, de 13 de fevereiro de 1995 ) instituiu uma exigência formal rigorosa para a comprovação do interesse público necessário à determinação da retomada do serviço ou bem objeto de concessão. Não basta decisão da autoridade administrativa (nem mesmo

A \& C R. de Dir. Administrativo e Constitucional, Belo Horizonte, ano 4, n. 16, p. 65-76, abr./jun. 2004 
do Chefe do Executivo) para que uma concessão seja extinta por razões de interesse público. A legislação geral em matéria de concessões exige que referida decisão seja objeto de deliberação do Poder Legislativo. O Poder Concedente, em relação a este assunto, há de se manifestar validamente por meio de lei e não apenas de ato administrativo.

Referido condicionamento está previsto de modo expresso no art. 37 da Lei ${ }^{\circ} 8.987 / 95$. Confira-se:

Art. 37. Considera-se encampação a retomada do serviço pelo poder concedente durante o prazo da concessão, por motivo de interesse público, mediante lei autorizativa específica e após prévio pagamento de indenização, na forma do artigo anterior.

Não há dúvida, portanto, quanto à necessidade de autorização legislativa específica para que ocorra a encampação. Esta é uma imposição do regime geral previsto para os contratos de concessão, de acordo com o ordenamento jurídico brasileiro.

No caso posto, a dificuldade está em saber se a referida lei específica pode ser Estadual — da entidade a quem coube "administrar" a concessão — ou se seria necessária a edição de lei específica Federal — por se tratar da entidade titular do bem objeto da concessão. Vejamos, pois, como a delegação da administração das rodovias, realizada pela União ao Estado, reflete na autorização legislativa para realizar a encampação.

\subsection{A delegação de rodovias federais ao Estado e a competência para editar lei autorizativa de encampação}

Será que a autorização para encampação da concessão rodoviária derivada de delegação federal pode ser feita em lei estadual? Uma resposta positiva poderia basear-se no raciocínio segundo o qual, se foi o Estado quem realizou o procedimento de licitação e firmou o contrato de concessão, também seria ele o responsável por determinar sua extinção, inclusive nos casos de encampação (extinção do contrato por razões de interesse público). Como a encampação depende de lei autorizativa, esta lei seria estadual, na medida em que determinaria conduta a ser implementada pela Administração do Estado (o responsável pela concessão).

É necessário, porém, verificar se essa visão se compatibiliza com a legislação que rege a delegação de bem público federal e as concessões de um modo geral.

O primeiro aspecto importante da legislação diz respeito à

A \& C R. de Dir. Administrativo e Constitucional, Belo Horizonte, ano 4, n. 16, p. 65-76, abr./jun. 2004 
titularidade do bem objeto da concessão. A lei que disciplinou a matéria Lei $\mathrm{n}^{\circ}$ 9.277, de 10 de maio de 1996 - preserva a titularidade federal dos bens objeto de delegação. Mostra disso está, de um lado, na transitoriedade da delegação, cujo prazo máximo é de 25 (vinte e cinco) anos renovável por igual período, findo o qual o bem retorna à administração da União $\left(\operatorname{art.} 1^{\circ}\right)$. Além disso, vale destacar que, mesmo sob o regime de delegação, a Lei $n^{\circ}$ 9.277/96 confere às rodovias e portos tratamento de bens federais, chegando até a autorizar a destinação de recursos da União para a realização de obras que os beneficiem $\left(\operatorname{art} .5^{\circ}\right) .^{2}$

Mas o ponto fundamental que refuta por completo a interpretação segundo a qual o Estado (delegatário do bem) teria competência para editar lei autorizativa da encampação está no próprio objeto da delegação, tal qual previsto na Lei $\mathrm{n}^{\circ} 9.277 / 96$. Deveras, logo em seu art. $1^{\circ}$, a lei foi clara ao delimitar a natureza da competência que estava sendo transferida. $\mathrm{O}$ texto legislativo fixou expressamente que a delegação envolvia tão somente a administração de determinados bens federais. Confira-se o dispositivo em referência:

Lei $\mathrm{n}^{\circ} 9.277$, de 10 de maio de 1996

Art. $1^{\circ}$ Fica a União por intermédio do Ministério dos Transportes, autorizada a delegar, pelo prazo de até 25 (vinte e cinco) anos, aos municípios, estados da Federação ou ao Distrito Federal, ou a consórcio entre eles, a administração de rodovias e exploração de trechos de rodovias, ou obras rodoviárias federais.

A lei autorizou a delegação de competência administrativa da União; não de competência legislativa. Esta diferença é muito relevante para a análise do problema. A Lei no 9.277/96 admitiu a delegação da administração de bens federais para Estados, Distrito Federal ou Municípios. Dentro desta delegação, autorizou expressamente até mesmo a utilização do instrumento jurídico da concessão pelas entidades delegatárias, de modo a que estas viessem a outorgar a particulares a exploração direta desses bens. É o que consta do art. $4^{\circ}$ da referida Lei:

Art. $4^{\circ}$ Para a consecução dos objetivos indicados nesta Lei, poderá o Município, o Estado ou o Distrito Federal explorar a via ou o porto diretamente ou através de concessão, nos termos das leis federais, que regem as concessões e da Lei 8.630, de 25 de fevereiro de 1993.

\footnotetext{
2 "Art. $5^{\circ}$ A união poderá destinar recursos financeiros à construção, conservação, melhoramento e operação das rodovias ou trechos de rodovias e obras rodoviárias federais ou aos portos, objeto de delegação, desde que tais obras e serviços não sejam de responsabilidade do concessionário."
}

A \& C R. de Dir. Administrativo e Constitucional, Belo Horizonte, ano 4, n. 16, p. 65-76, abr./jun. 2004 
Todavia, ao autorizar o emprego da concessão dos bens a particulares, a Lei não fez qualquer menção (expressa ou implícita) à substituição da função legislativa federal pela de Estados ou Municípios. Como deixa evidente o já mencionado art. $1^{\circ}$ da Lei $n^{\circ} 9.277 / 96$, a titularidade dos bens delegados permanece federal, e, principalmente, a delegação teve como objeto apenas a função administrativa. Portanto, há de se entender que a utilização do instituto da concessão em relação a esses bens delegados transfere às respectivas entidades delegatárias somente competências de índole administrativa da União.

Estados, Distrito Federal e Municípios delegatários podem promover licitações, celebrar contratos, fiscalizar a execução dos contratos, aplicar sanções, homologar tarifas, etc. A específica competência para autorizar a encampação, porém, como atribuição legislativa que é (art. 37 da Lei $\mathrm{n}^{\circ}$ 8.987/95), não foi objeto de delegação. A autorização desta medida cabe ao legislador federal; ao legislador da entidade titular do bem concedido, ou seja, ao Congresso Nacional. Somente após a autorização do Legislativo Federal é que se torna possível a tomada de providências administrativas por parte do Estado delegatário para a execução da medida (levantamentos de valores para pagamento de indenização, etc.).

Interessante ainda notar que a Lei $\mathrm{n}^{\circ}$ 9.277/96 mencionou matérias em que caberia aplicação de leis estaduais e municipais. Fez isto de modo expresso e sem se referir à autorização legislativa para a encampação. Deveras, apenas a matéria tarifária mereceu expressa autorização para se submeter à competência legislativa das entidades delegatárias. É o que se encontra no art. $3^{\circ}, \S 1^{\circ}$ da referida Lei:

Lei $\mathrm{n}^{\circ}$ 9.277, de 10 de maio de 1996

Art. $3^{\circ}$ A delegação será formalizada mediante convênio.

$\S 1^{\circ}$ No instrumento de convênio constará cláusula prevendo a possibilidade de aplicação da legislação do Município, do Estado ou do Distrito Federal na cobrança de pedágio ou de tarifa portuária, ou de outra forma de cobrança aplicável, no que não contrariar a legislação federal.

Com base no exposto, é possível chegar a uma segura interpretação da competência para editar lei autorizativa de encampação sobre bens públicos federais delegados, nos termos da Lei $n^{\circ}$ 9.277/96. Como a lei que autoriza a delegação se refere exclusivamente à transferência de competência administrativa $\left(\operatorname{art.~} 1^{\circ}\right)$, Estados, Distrito Federal e Municí- 
pios não podem encampar os bens federais objeto de delegação com base apenas em lei própria. Tal medida extrapola a competência administrativa da União, a única que foi objeto de delegação. Encampar implica precipuamente o exercício de competência legislativa, que pertence originariamente à União — titular do bem — e que não é objeto de transferência.

Esta conclusão está perfeitamente de acordo com a sistemática geral, implementada com base na Lei ${ }^{\circ}$ 9.277/96. Referida lei, muito embora autorize a delegação da gestão de bens federais a outras entidades da Federação, não buscou, com isso, alijar a União do processo de tomada de decisões estratégicas a respeito de tais bens. Essa característica ficou marcada em algumas passagens da legislação.

Primeiro, a delegação autorizada pela Lei no 9.277/96 não importou a transferência da titularidade do bem em si, que continua pertencendo à União; a delegação diz respeito apenas à gestão do bem, que pode passar para Estados, Distrito Federal ou Municípios.

Outro ponto marcante desta influência está no mecanismo previsto para formalizar a transferência. A delegação dos bens federais só pode ser efetuada mediante a celebração de convênio, por meio do qual a União fixa parâmetros específicos para a gestão do bem a ser delegado. Não foi por outra razão que foi necessário aprovar convênios específicos entre a União e o Estado do Paraná, p.ex. Tais convênios, além de instituírem um mecanismo próprio para a gestão desses bens (que seria a outorga de concessões a particulares), prescreveram a necessidade de aprovação prévia da Administração Federal para a implementação de qualquer mudança significativa no plano originalmente aprovado.

Em vista dessas características, nada mais lógico que, para se tomar uma decisão tão relevante como a encampação das rodovias, seja imprescindível a manifestação do titular do bem (União). No caso, esta manifestação, por se tratar de encampação, só pode ser feita por meio de lei federal específica.

Verificada a necessidade de autorização expressa do legislativo federal para a encampação que venha a ser estabelecida sobre concessão de bem público federal, submetido a delegação a outros entes federativos, passaremos a analisar outro aspecto marcante da participação da União neste processo: sua responsabilidade patrimonial.

\section{Responsabilidade patrimonial da União em virtude}

A \& C R. de Dir. Administrativo e Constitucional, Belo Horizonte, ano 4, n. 16, p. 65-76, abr./jun. 2004 


\section{de encampação}

\subsection{Participação da União na decisão de encampar}

Apesar de a delegação de bens federais implicar a transferência de sua administração a outras entidades, não é possível duvidar, conforme demonstrado no item anterior, que ainda foi preservada significativa participação da União em relação à definição dos destinos de seus bens delegados. De acordo com o sistema legal instituidor da delegação, a União ainda figura: a) como titular do bem; b) como entidade delegante da administração do bem, que detém a prerrogativa de, por meio de convênio especificamente celebrado, definir as diretrizes gerais para a gestão do bem delegado; c) como esfera legislativa competente para autorizar a encampação do bem; e d) como última beneficiária dos investimentos feitos sobre o bem delegado, uma vez que, ao término da delegação, este bem retorna ao seu patrimônio.

Diante deste quadro, já seria despropositado sustentar a completa ausência de responsabilidade do Poder Público Federal, por danos causados a particulares que tenham assumido a gestão do bem (mediante concessão).

Como foi visto no item anterior, em decorrência do próprio regime jurídico introduzido pela Lei $\mathrm{n}^{\circ} 9.277 / 96$, combinado com as regras da lei geral de concessões (Lei n $\left.{ }^{\circ} 8.987 / 95\right)$, a decisão de encampar necessita, em primeiro lugar, de uma decisão legislativa da União. Dano derivado de encampação em casos tais, portanto, contaria com a participação ativa da União, nem que fosse apenas no plano Legislativo (competente para autorizar a implementação da medida).

Não bastasse esse envolvimento do Legislativo — que é preliminar e fundamental — o modo de implementar a delegação deixou evidente que também deve existir participação da Administração Federal em decisões que levem à encampação do contrato de concessão. Esta é uma exigência dos próprios convênios, que formalizaram a delegação dos bens.

Os convênios são os instrumentos jurídicos que instituem e disciplinam a delegação dos bens federais a outras entidades (Estados ou Municípios). A lei autorizativa da delegação de bens federais a outras entidades federativas, ao fixar as linhas gerais desta fórmula, impôs a celebração de convênio como o mecanismo apto a instituir a transferência desses bens. ${ }^{3} \mathrm{O}$ convênio, portanto, é o elemento constitutivo da relação jurídica que vincula a

\footnotetext{
${ }^{3}$ Conferir art. $3^{\circ}$ da Lei n 9.277/96: "A delegação será formalizada mediante convênio."
}

A \& C R. de Dir. Administrativo e Constitucional, Belo Horizonte, ano 4, n. 16, p. 65-76, abr.jun. 2004 
União (entidade delegante) à entidade delegatária. Nesta condição os convênios apresentam como fundamental objetivo precisar os deveres e obrigações assumidos pelas partes.

Os convênios celebrados entre a União e o Estado do Paraná estabeleceram, de modo evidente, a participação mútua das entidades conveniadas na fixação das linhas gerais relacionadas à gestão do bem público objeto de delegação.

Esta característica do regime jurídico instituído pelos convênios é identificável em três normas principais. A primeira delas é a que impõe o dever de a União aprovar previamente o programa a ser implementado para a administração da rodovia delegada. ${ }^{4} \mathrm{Na}$ mesma linha, existe também a obrigação de submeter à União, previamente, qualquer alteração relevante no programa inicial. ${ }^{5}$ Deste modo, resta demonstrado que qualquer decisão importante no que tange à administração do bem delegado deve ser tomada de modo compartilhado. Tanto é assim no momento de implementação da parceria (instituição do programa), quanto em eventuais mudanças que venham a ser implementadas ao longo da delegação. As principais decisões relacionadas à gestão do bem público federal, enquanto perdurar a delegação, são tomadas de modo compartilhado entre a União (titular do bem) e a entidade delegatária (que, no caso, é o Estado do Paraná).

A terceira e última norma fundamental, que indica o caráter compartilhado das principais decisões sobre administração do bem, está no regime de extinção dos convênios. Faz parte do pacto que vincula a União e o Paraná, uma cláusula segundo a qual quaisquer das partes pode denunciar o acordo por razões de conveniência e oportunidade. Como condição para o fim da relação jurídica foi imposto apenas o dever de notificação com trinta dias de antecedência. ${ }^{6}$ Qualquer decisão tomada

\footnotetext{
${ }^{4}$ Confira-se o teor da cláusula terceira dos convênios firmados entre União e Paraná: "CLÁUSULA TERCEIRA — DA FORMA DE ADMINISTRAÇÃO DAS RODOVIAS E EXPLORAÇÃO DOS TRECHOS DE RODOVIAS FEDERAIS: O DELEGATÁRIO exercerá a administração e a exploração das rodovias e dos trechos rodoviários delegados mediante concessão, de acordo com o programa aprovado pelo DELEGANTE, que passa a fazer parte integrante deste Convênio, independentemente de transcrição."

5 "CLÁUSULA QUARTA - DAS OBRIGAÇ̃ES: 1. Incumbe ao ESTADO DO PARANÁ, na qualidade de DELEGATÁRIO: (...) IX - submeter ao Ministério dos Transportes qualquer alteração do programa inicial;". Nesta linha, convém também mencionar modificação implementada, via aditamento, na cláusula LIII, item 3, dos contratos de concessão de rodovia, que passaram a prever expressamente a participação da União em decisões que impliquem modificações unilaterais promovidas pelo Estado do Paraná. Confira-se o atual teor da cláusula: "3. Qualquer alteração unilateral deste CONTRATO, que modifique os encargos da CONCESSIONÁRIA somente poderá ser efetivada com prévia autorização da União, e deverá contemplar, concomitantemente, o restabelecimento do seu inicial equilíbrio econômico e financeiro, sendo submetida, de imediato, já previamente ao início da vigência da dita alteração unilateral, à confirmação de pelas Comissões de Peritos referidas na Cláusula LII deste CONTRATO".
} 
unilateralmente, de lado a lado, pode ensejar a ruptura do convênio, com a devolução do bem à administração direta da União. Se alguma postura desejada pelo Estado não for aceita pela União ou vice-versa, estaria plenamente aberta a possibilidade de extinção do convênio. A manutenção do acordo significa, implicitamente, que as partes concordam, compactuam, a respeito das decisões implementadas em relação à gestão do bem objeto de delegação. Houvesse desacordo entre as partes, haveria certamente a denúncia do convênio por qualquer uma delas.

Na hipótese de encampação que se cogita, a participação conjunta de União e Estado é marcante. A iniciativa da retomada do serviço é estadual, mas, para ser implementada, carece de aprovação administrativa e legislativa da União. Lei federal precisa ser editada para que a encampação do bem público pertencente à União venha a ocorrer de modo válido (conforme apontado no item anterior). Também é necessário, nos termos pactuados em convênio, que a União, por meio do Ministério dos Transportes, aprove expressamente esta importante alteração no programa original da administração dos bens (que, com a encampação, deixaria de ser feita por meio de concessão, conforme previsto inicialmente, e passaria a se desenvolver diretamente pelo Estado do Paraná). Vale ainda salientar que, se não houvesse concordância entre as entidades envolvidas, qualquer delas poderia denunciar o convênio, devolvendo-se a administração do bem à União. Assim, a pura e simples preservação do convênio, após a efetivação de uma medida como a encampação, é mostra de que houve efetiva aceitação da providência por parte das entidades envolvidas.

\subsection{Responsabilidade decorrente da participação da União}

Conforme demonstrado acima, é inegável a participação da União em decisão que determine a encampação dos contratos de concessão de rodovias federais, celebrados por intermédio do Estado. Resta, portanto, demonstrar que espécie de conseqüência patrimonial deriva deste envolvimento. Ou seja, qual a sua responsabilidade por eventuais prejuízos decorrentes deste ato de encampação.

A encampação é uma forma de extinção de contratos de concessão

\footnotetext{
"CLÁUSULA DÉCIMA-SEGUNDA - DA DENÚNCIA: As partes poderão denunciar o presente Convênio, mediante notificação, com trinta dias de antecedência. $§ 1^{\circ}$ Constituem motivos para a denúncia deste Convênio a superveniência de ato, fato ou lei que o torne inviável, a conveniência administrativa devidamente justificada ou o inadimplemento de quaisquer de suas cláusulas e condições, responsabilizando-se a parte que der causa à denúncia pelas respectivas indenizações."
}

A \& C R. de Dir. Administrativo e Constitucional, Belo Horizonte, ano 4, n. 16, p. 65-76, abr.jun. 2004 
que, por sua própria natureza, produz efeitos patrimoniais negativos ao concessionário. Deveras, por seu intermédio o contrato chega precocemente ao fim. Conseqüentemente, a exploração econômica do bem ou serviço delegado também termina antes do previsto, eliminando o instrumento para a amortização dos investimentos e a obtenção do retorno econômico-financeiro previsto contratualmente. Não é por outra razão que a própria lei geral de concessões prevê, como condição para a efetivação desta forma de extinção contratual, o pagamento de prévia indenização.

Trata-se de responsabilidade derivada de dispositivos expressamente previstos em Lei, cujos critérios de aferição são disciplinados contratualmente. Aplica-se ao caso, portanto, a chamada "responsabilidade contratual" da Administração Pública. ${ }^{7}$ Ao contrário da hipótese de "responsabilidade extracontratual", o dever de indenizar não é conseqüência pura e simples da provocação de um dano pelo Poder Público; a indenização é reflexo direto de obrigação previamente estabelecida em contrato e na legislação.

A obrigação de indenizar, neste caso, reai sobre quem tiver produzido o ato de encampação. ${ }^{8}$ Como visto no item anterior, porém, tanto o Estado quanto a União detêm importantes atribuições para a efetivaçãoda medida. Em tese, é possível que o Estado assuma sozinho o ônus econômico pela encampação. Todavia, só poderá fazê-lo se houver prévia aprovação da medida pela União (por meio de lei específica e aprovação do Ministério dos Transportes). A União, por sua vez, poderia assumir inteira ou parcialmente esse ônus econômico, por via de um acordo com a entidade delegatária da rodovia (o Estado). ${ }^{9}$ Não se pode esquecer que o Ente Federal ainda poderia, denunciando o convênio, assumir para si toda a execução do contrato de concessão para preservá-lo. ${ }^{10}$

Em resumo, a legislação que autorizou a delegação de bens federais

\footnotetext{
7 Trata-se, na terminologia empregada por Philippe Terneyre, de uma responsabilidade contratual sem culpa (responsabilité contractuelle sans faute). Isto se deve ao fato de incidir sobre a Administração contratante, uma responsabilidade derivada do contrato, mas sem que tenha ocorrido a produção de ato ilícito (descumprimento do contrato), uma vez que a extinção prematura e unilateral da avença é admitida pelas normas jurídicas aplicáveis (La Responsabilité Contractuelle des Personnes Publiques en Droit Administratif. Paris: Ed. Economica, 1989, p. 149).

${ }^{8}$ Código Civil: "Art. 942. Os bens do responsável pela ofensa ou violação do direito de outrem ficam sujeitos à reparação do dano causado; e, se a ofensa tiver mais de um autor, todos responderão solidariamente pela reparação. Parágrafo único. São solidariamente responsáveis com os autores os co-autores e as pessoas designadas no art. 932."

${ }^{9}$ A solução seria até plausível, uma vez que os benefícios realizados pela empresa concessionária estão vinculados a bem de sua titularidade e, por definição legal e contratual, são a ela reversíveis.

${ }^{10}$ Citamos mais uma vez o convênio assinado com o Estado do Paraná: "CLÁUSULA DÉCIMA-SEGUNDA - DA
}

A \& C R. de Dir. Administrativo e Constitucional, Belo Horizonte, ano 4, n. 16, p. 65-76, abr./jun. 2004 
a Estados da Federação e Municípios (Lei no 9.277/96) e que disciplina o instituto da concessão de serviço ou bem público (Lei $\mathrm{n}^{\circ}$ 8.987/95) determinou a divisão de atribuições para a tomada de decisão de encampar os contratos de concessão em exame. Esta conclusão também pode ser inferida do acordo de vontades que proporcionou esta delegação administrativa, uma vez que as partes envolvidas (União e Estado) autorizaram contratualmente a denúncia a qualquer tempo do convênio e fixaram a reversão final das benfeitorias ao patrimônio da União. ${ }^{11}$

Assim, há de se concluir que tanto a União quanto o Estado podem assumir o ônus da indenização decorrente da encampação. Tratase de responsabilidade solidariamente fixada para as entidades públicas relacionadas com o contrato de concessão a ser extinto: o Estado, que firmou o contrato com a empresa concessionária; e a União, a quem compete autorizar (administrativa e legalmente) a adoção da medida e a quem reverterá, em último grau, os investimentos feitos na rodovia em virtude do contrato a ser extinto.

Qualquer dessas partes pode assumir, voluntariamente, as despesas decorrentes da encampação. Qualquer discussão a respeito de rateio dessas despesas haverá de ser travada entre as entidades públicas envolvidas. ${ }^{12}$ Uma vez satisfeita a dívida por uma das partes, individualmente, eventual discussão a respeito de rateio da indenização ficará restrita às partes solidariamente responsáveis. Caso não haja pagamento, ou sendo este efetivado de maneira parcial, a empresa concessionária terá o direito de buscar a indenização de qualquer das partes envolvidas. Isto é, a concessionária terá direito de exigir o pagamento do Estado ou da União, indistintamente. $\mathrm{O}$ credor é alheio à discussão envolvendo a divisão da dívida entre os co-responsáveis, sendo-lhe legalmente reconhecido o direito de escolher quem lhe aprouver para realizar a cobrança direta. ${ }^{13}$

Há de se concluir, portanto, que a União é solidariamente responsável

DENÚNCIA: (...) §2 A denúncia deste Convênio, por qualquer das partes, não prejudicará o contrato de concessão dele decorrente."

11 A solidariedade, portanto, não é presumida, mas diretamente estabelecida pelo regime legal e contratual aplicável ao caso. Atende-se, assim, a prescrição do Código Civil para caracterização da responsabilidade solidária: "Art. 265. A solidariedade não se presume; resulta da lei ou da vontade das partes."

12 Código Civil: "Art. 283. O devedor que satisfaz a dívida por inteiro tem direito a exigir de cada um dos codevedores a sua quota, dividindo-se igualmente por todos a do insolvente, se houver, presumindo-se iguais, no débito, as partes de todos os co-devedores." "Art. 285. Se a dívida solidária interessar exclusivamente a um dos devedores, responderá este por toda ela para com aquele que pagar."

${ }^{13}$ Código Civil: "Art. 275. O credor tem direito a exigir e receber de um ou de alguns dos devedores, parcial ou totalmente, a dívida comum; se o pagamento tiver sido parcial, todos os demais devedores continuam obrigados solidariamente pelo resto."

A \& C R. de Dir. Administrativo e Constitucional, Belo Horizonte, ano 4, n. 16, p. 65-76, abr.jun. 2004 
com o Estado, caso haja a encampação dos contratos de concessão em exame. As partes envolvidas podem negocialmente resolver a quem caberá proceder à indenização do concessionário, em virtude da encampação. Todavia, a empresa concessionária terá direito de exigir o pagamento da entidade que entender conveniente, independentemente da solução interna que eventualmente venha a ser pactuada entre União e Estado.

A \& C R. de Dir. Administrativo e Constitucional, Belo Horizonte, ano 4, n. 16, p. 65-76, abr./jun. 2004 